\title{
JUSTICIA TRANSICIONAL Y DERECHO A LA REPARACIÓN INTEGRAL. APROXIMACIÓN AL CASO COLOMBIANO
}

\author{
Enrique Cáceres Mendoza \\ UniversidAd NaCiONAL de COLOMBIA
}

\section{Resumen}

A pesar de que en los últimos años se han adelantado en Colombia diferentes esfuerzos por parte del Estado para garantizar la reparación integral a las víctimas de violaciones a los derechos humanos como parte de una política social gubernamental, la realidad permite sostener que aún han quedado muchas tareas pendientes frente a la exigibilidad y materialización de estas garantías sociales, colectivas e individuales, sobre todo en momentos en los que se pretende construir un marco jurídico de justicia transicional, mientras aún se reproducen las condiciones propias del conflicto armado interno no declarado. La realidad social, económica y política en la que se adelantan ingentes esfuerzos por obtener un acuerdo de paz con una facción de los actores armados del conflicto supone un acercamiento a la construcción de unas condiciones que redundarán en la producción de normas de transición.

Palabras clave: conflicto armado, reparación integral, derechos humanos, víctimas.

El autor: abogado, magíster en Derecho. Asesor de la Dirección Nacional de Personal de la Universidad Nacional de Colombia. Dirección postal: transversal 71 No. 2A-66, interior 8, apartamento 502, Bogotá. Correo electrónico: aecaceresm@unal.edu.co

Recibido: 14 de agosto de 2013; evaluado: 21 de octubre de 2013; aceptado: 25 de noviembre de 2013. 


\title{
TRANSITIONAL JUSTICE AND RIGHT TO INTEGRAL REPARATION. AN APPROACH TO THE COLOMBIAN CASE
}

\author{
Enrique Cáceres Mendoza \\ UniversidAD NaCiONAL de COLOMbIa
}

\begin{abstract}
Despite the various efforts made by the Colombian state to guarantee the integral reparations for victims of human rights violations as part of a government social policy, the reality allows to argue that many tasks are pending in regards to the enforcement and realization of these social, collective and individual rights; especially in times when a legal framework of transitional justice is to be built, while the typical conditions of an internal undeclared armed conflict are still reproduced. The social, economic and political context in which enormous efforts are done in order to get a peace agreement with a faction of the conflict armed actors would lead to an approach for building some conditions that will result in the production of transition rules.
\end{abstract}

Keywords: armed conflict, integral reparations, human rights, victims.

About the author: Lawyer, Master of Law. Consultant at Dirección Nacional de Personal (Talent management division) of Universidad Nacional de Colombia. Address: transversal 71 No. 2A-66, interior 8, apartamento 502, Bogotá. E-mail: aecaceresm@unal.edu.co

Received: August 14, 2013; reviewed: October 21, 2013; accepted: November 25, 2013. 


\section{Introducción}

El presente documento forma parte de la investigación realizada para la obtención del título de magíster en Derecho, con profundización en Derechos Humanos y Derecho Internacional Humanitario, de la Universidad Nacional de Colombia en septiembre de 2013. Se tituló ¿Reparar?, bueno, sí. pero, ¿por qué?: una mirada hacia la fundamentación de la obligación de reparar integralmente a las víctimas en Colombia, en la cual se sostuvo que la materialización efectiva del derecho fundamental a la reparación integral de las víctimas en Colombia, como parte de un proceso social de reconstrucción, ha sido insuficiente, toda vez que se ha corrido el serio riesgo de asignar a la política de Estado de reparación a víctimas el papel de una propuesta programática electoral y no la de un real compromiso del Estado ante un fenómeno social estructural asociado con la violencia como hecho generador de obligaciones internacionales y de acercamiento a la materialización de la justicia.

En tales condiciones, mediante variados instrumentos jurídicos, las víctimas en Colombia han procurado buscar una tutela efectiva de sus derechos, aunque en la mayoría de los casos, esta clase de reclamaciones se ha tenido que formular por la conexidad con otros derechos fundamentales, debido a la ausencia de una visión integrada de la reparación, la justicia y la verdad como derechos fundamentales, que han conllevado a que durante mucho tiempo se genere un ambiente de desconocimiento y denegación de la atención a las víctimas.

Es imprescindible examinar, a la luz del Derecho Internacional de los Derechos Humanos y con referencia en algunos casos o experiencias internacionales, las vivencias sociales, jurídicas, económicas y culturales que alimentan en Colombia el escenario en el que se busca formular una justicia de transición y tener en cuenta las condiciones reales y objetivas del conflicto colombiano, así como las alternativas propias para su superación, para la construcción de un modelo transicional jurídico y político que responda a los intereses de toda la sociedad y, en particular, la responsabilidad ante las víctimas directas e indirectas del conflicto. La sola promulgación y entrada en vigencia de leyes o marcos transicionales de justicia no es garantía suficiente para la recomposición social de un país que sufre un conflicto armado de más de seis décadas, derivado de diferentes factores estructurales que no se pueden desconocer a la hora de expedir leyes en busca de una nueva sociedad. 


\section{Justicia transicional y víctimas}

Hablar de justicia transicional por lo general se asocia con la idea de un conjunto de normas que pretenden crear condiciones jurídicas, sociales y políticas para la recomposición de una sociedad que ha pasado por graves situaciones de crisis humanitarias o de regímenes políticos en los que el autoritarismo es el común denominador y avanza hacia sistemas políticos más democráticos y participativos. ${ }^{1}$ Mas el concepto de justicia transicional implica, desde una perspectiva integrada y sistémica, no solo la existencia de un tránsito político y social hacia unas nuevas condiciones de vida en una determinada sociedad; vista y entendida desde una concepción más profunda, constituye el conjunto de normas que compondrán los principales mecanismos jurídicos de lucha contra la impunidad ante la comisión de graves delitos contra el Derecho Internacional de los Derechos Humanos, cometidos en estados de anormalidad institucional como producto de desestabilizaciones democráticas o como resultado de conflictos internos que comprometen a sujetos de derecho interno e internacional.

Para entender el fenómeno de la justicia transicional, es necesario adoptar la idea de la reconciliación social como punto de partida para la reconstrucción humana, en la que desempeñará un papel protagónico la reivindicación de los derechos de las víctimas, como parte de un obligado proceso activo y dinámico que supone la asunción de responsabilidades por parte de los diferentes actores del conflicto, sea instituciones gubernamentales, cuerpos armados regulares o irregulares o demás instancias de poder; esto permite, en todo caso, la participación con suficiencia

Cuervo define la justicia transicional como el conjunto de normas que crean un ambiente de justicia "que se provee en el tránsito de una sociedad autoritaria a una sociedad democrática o a la finalización de un conflicto armado". Jorge Iván Cuervo, "Estándares internacionales de verdad, justicia y reparación. La aplicación de la Ley 975 de 2005 o Ley de "Justicia y paz" en Justicia transicional: modelos y experiencias internacionales, a propósito de la ley de justicia y paz, ed. Jorge Iván Cuervo Restrepo, Eduardo Bechara Gómez y Verónica Hinestroza Arenas (Bogotá: Universidad Externado de Colombia, 2007), 17.

En tanto, para la Corte Constitucional colombiana, conforme a lo sostenido en Sentencia C-052 de 2012, la justicia transicional es "una institución jurídica a través de la cual se pretende integrar diversos esfuerzos, que aplican las sociedades para enfrentar las consecuencias de violaciones masivas y abusos generalizados o sistemáticos en materia de derechos humanos, sufridos en un conflicto, hacia una etapa constructiva de paz, respeto, reconciliación y consolidación de la democracia, situaciones de excepción frente a lo que resultaría de la aplicación de las instituciones penales corrientes". Ambas concepciones, por supuesto, conducen a examinar la acepción como un conglomerado de instituciones jurídicas y políticas que suponen, por definición misma, un cambio de condiciones y el paso de una situación a otra, bien sea la superación de un régimen autoritario o bien la superación de un estado de violaciones masivas y sistemáticas a los Derechos Humanos, pero es lógico que la producción de las normas de dicho marco deberán obedecer a la inminente transformación de condiciones objetivas que permitan suponer, asimismo, la transición social en la que se aplicarán. 
de la sociedad civil y las organizaciones defensoras de Derechos Humanos. ${ }^{2}$ El rol que han asumido múltiples organizaciones no gubernamentales, fundaciones en defensa de las víctimas y defensores de detenidos políticos, entre muchas formas de organización de la sociedad civil, ha sido favorecido por las nuevas concepciones de las relaciones internacionales, al punto de ganarse un lugar especial dentro de la lucha contra la impunidad y los crímenes de Estado que, para las más recientes concepciones del Derecho Internacional, ya no es visto como el único responsable de la violación de Derechos Humanos. ${ }^{3}$

Muchas de las experiencias internacionales de transiciones políticas se han gestado a partir de la participación activa y decidida de organizaciones civiles y sociales que, ayudadas por la presión de la comunidad internacional, han sido fundamentales a la hora de reclamar y reivindicar derechos y garantías desconocidas en regímenes totalitarios o en situaciones de graves y sistemáticas violaciones a los derechos humanos. Varios ejemplos han permitido observar cómo, a pesar de los escenarios de violencia, terrorismo de Estado o empoderamiento de fuerzas totalitarias, los grupos humanos que forman parte de la sociedad no institucional han sido factor clave en la lucha contra la impunidad y el olvido y que, en procura de obtener

2 La adopción de la responsabilidad jurídica en materia de derechos humanos, bajo esta perspectiva, es consecuencia directa del examen que se hace de tales derechos no solo como postulados enunciativos de derechos, sino como verdaderas categorías jurídicas de orden superior. Como tales, estas enunciaciones normativas comportan garantías reales de los individuos que prevalecen sobre el mismo poder del Estado, al punto de constituirse en verdaderos "límites al ejercicio del poder público en el Estado constitucional y democrático de derecho", acepción que, en definitiva, destaca el papel activo del individuo ante el poder del Estado, que ya no se hace absoluto y que sí adquiere un papel de responsabilidad ante los sujetos, por expreso mandato jurídico positivo, con lo que deja de lado la discusión clásica entre los contenidos del Derecho y los de la moral. Rodolfo Arango Rivadeneira, Derechos humanos como límite a la democracia: análisis de la Ley de Justicia y Paz (Bogotá: Norma, 2008), 82. En tales condiciones, la importancia que adquieren los derechos fundamentales en los nuevos sistemas jurídicos, en procura de encontrar el punto exacto de la correcta interpretación y materialización de postulados jurídicos enunciativos, por medio del texto constitucional, son factores determinantes para definir la responsabilidad en la salvaguarda de los mismos y, por consiguiente, la competencia frente a la obligación jurídica de responder ante su desconocimiento.

3 De acuerdo con los estudios más adelantados en la materia, el Derecho Internacional de los Derechos Humanos en términos de constitucionalismo moderno, así como en términos de integración jurídica a los estándares internacionales, poco a poco ha ido adoptando el criterio jurídico-político de la responsabilidad común por los daños causados; esta es un tipo de responsabilidad compartida, pero diferenciada, dado que, por un lado, la misma comunidad internacional se ha visto forzada a adquirir sobre sí la responsabilidad internacional por los daños causados a los extranjeros, a los mismos nacionales y, por otro, aún no se desconoce la idea clásica de su titularidad en los sujetos por excelencia del Derecho Internacional: los Estados. Es así como el Derecho se ha ido transformando y ha permitido que en los diferentes sistemas jurídicos internos sea cada vez más recurrente la adopción e imposición de aspectos universalmente considerados como elementales en el marco de la Justicia Penal Internacional, la homogenización o estandarización única del trato igual, sin nacionalidades o fronteras, en tanto supremacía de la protección de los bienes jurídicos a la vida, la integridad, la libertad y la seguridad personales. Jaume Ferrer Llorét, Responsabilidad internacional del Estado y derechos humanos: estudio de la práctica relacional e institucional (Madrid: Tecnos, Universidad de Alicante, 1998), 23 y ss. 
soluciones humanitarias, han llevado a la formación de nuevos contextos de acceso real y material a la justicia, reconocida tanto en fuentes internacionales de Derecho como en los ordenamientos positivos internos de cada Estado contemporáneo, que han obligado a las fuerzas institucionales a formular escenarios directos de justicia transicional como mecanismo remedial ante las injusticias y desmanes cometidos. ${ }^{4}$

El derecho a la justicia, en el marco de los modelos transicionales, corresponde a una categoría jurídica superior al ordenamiento jurídico corriente que, por su misma naturaleza, exige de las autoridades públicas el deber de hacer una reconstrucción social a partir de la búsqueda integral de la verdad material y procesal como uno de los pilares básicos de toda transición política. ${ }^{5}$ Además, los deberes de investigar, juzgar y sancionar a los responsables de violaciones masivas de derechos humanos forman parte del deber genérico de garantía que asumen los Estados en cuanto a respeto y materialización de los derechos de garantías judiciales, como paso previo a la reconstrucción del tejido social. ${ }^{6}$

Es necesario que los Estados respondan satisfactoriamente a las presiones de la comunidad internacional y de las organizaciones civiles ante la búsqueda de medios de justicia y recomposición social. Este es un primer paso importante para

4 Según la historia mundial reciente, la justicia transicional ha sido una respuesta casi obligada a la presión de la comunidad y la sociedad civil ante los abusos del poder o las diferentes muestras de masivas violaciones a los derechos humanos, tal como se encuentra en los ejemplos de Argentina, El Salvador, Guatemala o Chile, aunque muchas veces las condiciones normativas creadas con posterioridad a la caída de las dictaduras y la entrada en vigor de regímenes democráticos no fueron suficientes para garantizar la materialización de los derechos de las víctimas de los regímenes. Ethel Nathaly Castellanos Morales, Justicia transicional en Colombia. Formulación de propuestas desde un análisis comparado (Bogotá: Universidad Nacional de Colombia, 2008), 23.

5 Cuervo, "Estándares internacionales de verdad, justicia y reparación", 36.

6 Convención Americana de Derechos Humanos, Artículos 8 y 25, referidos a las obligaciones adquiridas por los Estados de investigar, juzgar y sancionar a responsables de violaciones a los derechos humanos, así como al deber de garantizar mecanismos de protección judicial. Estas normas de carácter internacional ya refieren a la obligación internacional que se asume por parte de los Estados, como sujetos de derecho internacional, de crear condiciones para evitar la reproducción de los modelos en los que se presentaron las violaciones a los derechos humanos, en especial por medio de sus autoridades públicas, al asignar a las autoridades judiciales un papel protagónico en términos de materialización de justicia, como parte de los componentes que constituyen la reparación integral desde su concepción más amplia en Derecho Internacional de los derechos humanos. Al respecto, es necesario acudir, como fuentes de Derecho Internacional, al Conjunto de Principios para la Protección y Promoción de los Derechos Humanos Mediante la Lucha Contra la Impunidad (1989), la Declaración de las Naciones Unidas sobre los Principios Fundamentales de Justicia para las Victimas de Delitos y del Abuso de Poder, adoptada por la Asamblea General de las Naciones Unidas el 29 de noviembre de 1985 y anexa a la Resolución 40/34, el Informe Final acerca de la cuestión de impunidad de los autores de violaciones de los Derechos Humanos, Derechos Civiles y Políticos y los Principios y Directrices Básicas sobre el Derecho de las Víctimas de Violaciones Manifiestas de las Normas Internacionales de Derechos Humanos y de Violaciones Graves del Derecho Internacional Humanitario a Interponer Recursos y Obtener Reparaciones, aprobados mediante Resolución No. 2005/35 del 18 de abril de 2005 por la Comisión de Derechos Humanos de las Naciones Unidas. 
redimensionar y redefinir los alcances del nuevo Derecho Internacional de los Derechos Humanos, más allá de los mecanismos de cooperación internacional o jurisdicciones universales, pues hoy por hoy no basta con la instrumentalización de herramientas normativas integradas a las legislaciones internas, si no existe un papel activo por parte de los Estados en cuanto a su obligación como sujeto de derechos, de participar en la reconstrucción de las sociedades.

Si bien es cierto que no existen sociedades perfectas que hayan encontrado equilibrio entre las demandas éticas y políticas que se exigirían en Estados de Derecho contemporáneos y sus consecuentes sistemas normativos de justicia, también resulta serlo que las transiciones sociales y políticas de las últimas décadas en varios lugares del mundo han demostrado que la lucha contra la impunidad ha tomado diferentes dimensiones, incluidos, el papel de las víctimas y su derecho a la reparación. ${ }^{7}$ Estas categorías se convierten, pues, en los pilares básicos inmersos en el concepto de justicia transicional, los cuales hacen referencia a la restauración del Estado de Derecho, la necesidad de enfrentar una cultura antiimpunidad, la restauración de la confianza en las instituciones estatales, la consolidación de la democracia y el compromiso de resarcir a las víctimas, entre otros aspectos que se encuentran cada vez más fortalecidos a partir de las experiencias de transformación de modelos autocráticos y totalitarios hacia sociedades más incluyentes. Estas experiencias de reconstrucción social, política y jurídica han demostrado que la reconciliación no involucra solo a las partes del conflicto, sino que se extiende a todos los sectores sociales, en tanto todos ellos pueden llegar a ser considerados como víctimas en situaciones de anormalidad institucional y crisis democráticas; esto supone, a su vez, que no por el solo hecho de generarse un marco jurídico transicional las sociedades queden exentas de volver a sufrir prácticas totalitarias o de crisis humanitarias como las que les antecedieron.

En estas condiciones, es importante resaltar el papel de las víctimas y considerar que el componente triple de la reparación — la verdad, la justicia y la reparación— es, en sí mismo, el punto de partida de cualquier intento de reconciliación social. No puede haber modelo normativo transicional de justicia sin tener en cuenta el rol protagónico de las víctimas, que son, en últimas, la razón de ser de la necesidad inminente de una transformación social, jurídica y política, conforme lo han demostrado las experiencias internacionales. ${ }^{8}$

Cuervo, "Estándares internacionales de verdad, justicia y reparación", 16.

8 La justicia transicional es entendida como un modelo en el que "para promover la justicia, la paz y la reconciliación, tanto funcionarios de gobierno como actores no gubernamentales buscan soluciones judiciales y no judiciales para esclarecer y dar cuenta de los abusos en sus variadas dimensiones, superar la impunidad, 
Hablar en este marco de referencia de los derechos de las víctimas implica reconocer que el valor fundamental de la justicia como Derecho tiene una doble connotación, de obligatoria observancia en todo modelo de justicia transicional: tanto el castigo a los responsables como la aceptación de la responsabilidad propia por parte del Estado. Lo anterior por cuanto la misma historia se ha encargado de demostrar la existencia de sociedades transicionales en las que, en aras de defender la democracia en formación, el retorno a sistemas más participativos del ejercicio político o la restauración de la democracia y a pesar de la multiplicidad de agentes y víctimas, la institucionalidad estatal ha sido insuficiente o ha adoptado actitudes pasivas ante las consecuencias mismas de los cambios transicionales, al desconocer los derechos individuales de las víctimas y los derechos colectivos de la sociedad a reclamar verdad y justicia.

Asimismo, el contenido del valor fundamental de la verdad como Derecho se entiende desde la multiplicidad de dimensiones que le es propia, esto es, el descubrimiento y la aceptación de la verdad jurídica, la verdad judicial, la verdad material y la verdad histórica, como piedras angulares de la reconstrucción social pretendida; esto abarca el derecho de las víctimas, consideradas individualmente o en conjunto, a conocer la realidad de los hechos, pero también a procurar la certeza de la lucha institucional contra la impunidad, como presupuestos independientes al derecho a obtener una reparación integral por las vías judiciales o administrativas previstas en los diferentes regímenes jurídicos institucionales. En este orden de ideas, los intereses personalísimos de la víctimas o sus familiares se confunden también con los intereses mismos de la sociedad general, que ya no solo pretenden un cambio social y jurídico, sino que exigen y reclaman con vehemencia las respuestas a múltiples inquietudes, que solo se pueden responder desde la perspectiva de la reclamación del derecho a la verdad como parte integrante de la reparación como categoría jurídica de primer orden. ${ }^{9}$

reconocer responsabilidades, reparar a las víctimas, dar lugar a la memoria y reformar instituciones para evitar similares sucesos en el futuro. En esos escenarios encuentra su campo la "justicia transicional". Su propósito en los términos más sencillos es lograr avanzar sobre la justicia a pesar de los desafíos del contexto y por razón de las oportunidades de cambio que éste ofrece. Los mecanismos de justicia en transición buscan definir contextos nuevos, en los que el respeto a los derechos humanos se convierta en una promesa real y cotidiana". Ómar Huertas Díaz, "Los derechos de las víctimas de las violaciones a los derechos humanos", en La dimensión internacional de los derechos a la verdad, a la justicia y a la reparación para las víctimas de violaciones a los derechos humanos (Bogotá: Grupo Editorial Ibáñez, 2008), 57-58.

9 Aura Patricia Bolívar Jaime introduce al respecto varios elementos recogidos en la jurisprudencia de la Corte Constitucional colombiana sobre el derecho de las víctimas a obtener una pronta y eficaz protección en materia de Reparación Integral y hace referencia a los diferentes matices que dicha figura ha venido siendo integrada al Derecho colombiano, tanto desde la modalidad de la reparación por vía judicial (como consecuencia de la decisión judicial que condena al Estado por su responsabilidad por acción u omisión en las violaciones 
Según ciertas experiencias internacionales, la reconstrucción que supone la transformación hacia una sociedad transicional, también se ha visto amenazada por el fantasma del olvido, de la impunidad y de la ignorancia. Los ejemplos históricos han demostrado que, bajo la excusa de la reconciliación social, los regímenes transicionales se han escudado en la adopción de medidas legislativas y administrativas de "perdón y olvido", que han llevado a la burla de los derechos de las víctimas, por ejemplo, mediante la adopción de figuras como las amnistías, los indultos, las leyes de punto final o de obediencia debida, en donde se ha roto el equilibrio que "debería existir" en las democracias en transición entre sociedad, Estado y víctimas. Otorgar perdón no debe implicar la generación de un clima de impunidad, sino más bien tratar de ubicarse en un punto intermedio entre la investigación y el juzgamiento de los responsables y la verdad material que tanto las víctimas como la sociedad misma reclama. Ello por cuanto es deber de los Estados no solo adoptar o implementar medidas de cambio, sino garantizar que se cumplan de manera efectiva y que las múltiples víctimas no vean vulnerados sus derechos fundamentales a la verdad y la memoria, si es que en realidad se pretende sanar las heridas sociales que se produjeron con las crisis desestabilizadoras.

Así, se debe resaltar que es un elemento fundamental de la democracia la exigencia de instrumentos eficaces de lucha contra la impunidad, que contribuyan a su legitimación y que, al mismo tiempo, doten de instrumentos jurídicos a los poderes judiciales para perseguir y sancionar a los responsables, aun cuando se hayan adoptado políticas de negociación entre estos y el Estado, sin dejar de lado que lo que se busca es una reinserción social en procura de la justicia como valor y derecho fundamental. Si el interés real de los sistemas transicionales es la paz y

a Derechos Humanos) como la reparación por vía administrativa, cuyos propósitos son: "El reconocimiento a las víctimas de su condición de ciudadanos con plenos derechos y por ende la recuperación de su dignidad y la de sus familiares; la recuperación de la confianza de los ciudadanos en las instituciones del Estado, y, aún más importante, la confianza entre los ciudadanos, reconstruyendo los lazos familiares y vecinales, es decir, el tejido social; proporcionar seguridad y confianza a las víctimas, restablecer la conciencia moral de la sociedad; y prevenir las causas para que no se repitan los hechos violatorios de derechos humanos". En esta misma línea, ya la reparación integral no es vista como una simple consecuencia jurídica derivada de una acción o de una omisión, participación que en los términos del Consejo de Estado, estuvo muy ligada a la teoría de la falla del servicio, capaz de originar sentencias en contra del Estado desde la óptica puramente jurídico procesal. La evolución del Derecho y las instituciones jurídicas han llevado a que la reparación adquiera la categoría de un Derecho de contenido fundamental, en tanto se vinculen a una idea de justicia que parte del reconocimiento de la dignidad humana misma, que se considera, desde una perspectiva teórica iusnaturalista, como un ser integral completo, en tanto goza de la totalidad de sus derechos y libertades. Aura Patricia Bolívar Jaime, "El derecho a la reparación integral y programas de reparación en perspectiva comparada" en Reparaciones en Colombia: análisis y Propuestas, comp. por Rodrigo Uprimny Yepes (Bogotá: Universidad Nacional de Colombia, 2009), 85. 
la adopción de la democracia, debe prevalecer entonces el equilibrio y la proporcionalidad entre justicia y verdad como elementos integradores de la sociedad. ${ }^{10}$

Una primera pregunta que surge es ¿cuál sería el papel de los aparatos judiciales del Estado en un contexto de justicia transicional, si el actual sistema penal internacional ofrece nuevos instrumentos de lucha contra el crimen internacional superiores a los ordenamientos internos? A simple vista, no se trata de un interrogante fácil de responder por el distanciamiento existente entre las figuras transicionales de justicia y la adopción de un sistema de jurisdicción universal, que no diferencia entre tránsitos políticos y sociales y graves violaciones a los derechos humanos.

Si la justicia transicional es aquella que se produce en los pasos de regímenes autoritarios o dictaduras hacia modelos democráticos o más participativos, dentro de los cuales el criterio de ponderación debe ser mucho más riguroso, por ejemplo, respecto a delitos de lesa humanidad, como los que son de competencia de la Corte Penal Internacional, se podría sostener que no habría cabida a pensar en que la negociación o salida de un conflicto para lograr una transición social pueda soslayar la intervención de la Corte, dado que esta tendría facultades para investigar, sancionar y condenar a los responsables por graves delitos como los contemplados en los Artículos 5 y siguientes del Estatuto de Roma, los cuales resultan, por su misma naturaleza, excluidos de las figuras a las que se dedica este modelo jurídico y político.

La dicotomía que en este sentido se plantea parece abordar dos problemas de especial consideración: por un lado, la titularidad del derecho que busca ser reparado y, por otro, la responsabilidad individual de quienes están comprometidos en graves crisis y violaciones a derechos humanos dentro de regímenes que están en tránsito a la restauración social que propone la justicia transicional. Dígase, en relación con lo primero, que la titularidad del derecho a la reparación integral, en su trípode verdad, justicia y reparación, no puede condicionarse solo a la voluntad política de los Gobiernos de turno, pues ya bastantes ejemplos históricos se han producido acerca de la manipulación política de los actores para salvaguardar sus integridades y evitar responsabilidades directas, como lo fue la aceptación social por vía de referendo de las Leyes de perdón y olvido en Uruguay después de la última

10 Castellanos Morales, Justicia transicional en Colombia, 159. Cabe anotar que no se puede pretender que la justicia transicional solo opere en cambios de regímenes hacia sociedades democráticas, pues son varios los ejemplos mundiales en los que la adopción de estos marcos jurídicos han tratado de servir de instrumentos para la recomposición social luego de profundas crisis humanitarias, en las que no necesariamente se encuentra comprometida la figura del poder dictatorial. 
dictadura civil (1973-1985), que abrió puertas para la impunidad y la negación de justicia hacia las víctimas.

Frente a lo segundo, el tema de la responsabilidad individual es la misma sociedad la que exige la adopción de medidas eficaces que permitan demostrar que la transición es una realidad para todas las esferas sociales y que ni siquiera quienes ostentaron altos grados de poder pueden escapar a la ley como expresión máxima de la soberanía y la voluntad popular, la cual está formulada en términos de reconstrucción social, pero también en términos de mecanismo idóneo para evitar la impunidad y la repetición de las condiciones que antecedieron a la restauración de la democracia o de la transformación hacia el modelo transicional de recomposición social.

El ejemplo de lo sucedido en Uruguay, en donde la dictadura civil tuvo un fuerte apoyo del poder militar, exhibió la realidad de una crisis social y humanitaria, en donde no solo se produjeron masivas violaciones a los derechos humanos, sino que también llevó a una delicada situación social y económica que tuvo gran participación de poderes internacionales en perjuicio del pequeño Estado latinoamericano. Como es de verse, los intentos de crear una adecuada justicia transicional en el país tuvieron que analizar, desde diferentes perspectivas, cómo solucionar crisis que no solo hacían referencia a las víctimas de violaciones a derechos humanos, sino que además tuvieran en cuenta la descomposición social y económica en la que se había sumido Uruguay luego del período de la dictadura, aunque las condiciones políticas y económicas subsiguientes desatarían otra clase de fenómenos y dificultades. ${ }^{11}$

Esta serie de elementos sugiere que el reconocimiento mismo de la condición de víctima forme parte integrante y fundamental del modelo de justicia transicional y

11 "Esta es la última imagen que me llevé de Montevideo: los enjambres de niños que revolvían la basura en busca de trapos, botellas y pan duro. Poco antes, los militares habían disuelto el Parlamento y todo lo demás. Pero ya, entre 1968 y el 73, el Uruguay había batido el récord mundial de suspensiones y clausuras de periódicos y hacía tiempo que el país venía produciendo más violencia que mercancías. Montevideo, con su vasto aparato burocrático, era desde siempre, el vertedero de todas las contradicciones. A sus puertas golpeaban, golpean todavía, los jóvenes sin trabajo. En el campo, negaba trabajo el latifundio, que ahora expulsa más gente, en la ciudad, negaban trabajo las fábricas, que trabajan ahora con mano de obra escasa y esclava. Una ciudad que abarcaba, como ahora, la mitad de la población del país, ¿no era síntoma de grave enfermedad nacional? Esperanza, fraude, furia: el sistema, administrado por espectros, odiaba a los jóvenes: la dictadura no hizo más que vengarlo. La clave del comercio exterior era, desde antes del golpe de Estado, el tráfico de carne humana. Como hoy, se exportaban trabajadores jóvenes y se importaban turistas. La sexta parte de la población uruguaya, corrida por la pobreza o por la policía, vive fuera de fronteras. El destierro masivo no empezó con la dictadura, aunque se aceleró con ella: incapaz de ofrecerles trabajo y libertad, es el sistema quien echa a los jóvenes". Eduardo Galeano, "Un amigo me pregunta cómo es Montevideo", en Nosotros decimos no. Crónicas 1963-1988, comp. Eduardo Galeano (Madrid: Tercer Mundo Editores, 1989), 260. 
es suficiente en sí mismo para demandar de todos los actores comprometidos — pero en particular, del Estado - las indemnizaciones y reparaciones correspondientes. Por otro lado, las ideas de reconciliación y perdón no pueden condicionarse a la potestad judicial del Estado, pues ello desconoce la supremacía de la justicia penal internacional, máxime cuando el propio Estatuto de Roma se vio afectado por la inclusión del llamado "principio de complementariedad", en virtud del cual la Corte solo podrá conocer de una investigación cuando un Estado no pueda o no quiera ejercer su poder jurisdiccional interno frente a alguno de los delitos de competencia de la Corte.

Si bien la Corte Penal Internacional tiene competencia para conocer de crímenes cometidos después de la entrada en vigor de su Estatuto matriz (Artículo 12 Estatuto de Roma, Competencia temporal), no puede pasarse por alto que al hablar de justicias transicionales no solo se han de tener como referentes los regímenes totalitarios de la segunda mitad del siglo XX que se propagaron por diferentes latitudes, pues es claro que los ejemplos actuales de las crisis sociales que se evidencian en Oriente Medio, Norte y Centro de África y algunos otros países en donde se han agudizado, durante décadas, los conflictos armados internos, permiten considerar que la Corte deberá tomar atenta nota de tales crisis para demostrar que su injerencia en el panorama mundial es superior a la que, en apariencia, tiene en la actualidad.

En estas condiciones, parece claro entonces que la Corte Penal Internacional resulta un actor adicional en el panorama actual de la justicia transicional, tanto en la búsqueda de soluciones negociadas a los conflictos como en los esfuerzos que se desarrollen para lograr estabilidades democráticas, en la medida en que la mayor participación de esta clase de entes supranacionales, además de convertirse en instrumentos internacionales de presión política y jurídica, también constituyen organismos garantes de la verdad y la justicia, aun por encima de la voluntad de los Estados. ${ }^{12}$

12 Así, dentro de los varios componentes de la reparación integral, la verdad surge como imperativo categórico de primer orden: "En los últimos tiempos, en la esfera del Derecho Internacional de los Derechos Humanos se ha vuelto recurrente el planteamiento del derecho a la verdad como un derecho humano inalienable, a pesar de su falta de reconocimiento específico en tratados y convenios internacionales, cuyo desarrollo se logra a partir de la doctrina y la jurisprudencia de tribunales internacionales, principalmente por medio de dos importantes documentos elaborados por la Comisión de Derechos Humanos de las Naciones Unidas, como son, "el Conjunto de Principios para la protección y promoción de los derechos humanos mediante la lucha contra la impunidad" y los "Principios y Directrices Básicos sobre el derecho de las víctimas de violaciones de los derechos humanos a interponer recursos y obtener reparaciones", que ha conducido no solamente al reconocimiento de la verdad como derecho de las víctimas y de la sociedad en general, cuya protección es responsabilidad de los Estados, sino a establecer los mecanismos a través de los cuales se pretende su materialización, principalmente en aquellos lugares y momentos en los que las sociedades afrontan procesos de transición a la democracia y/o a la paz o a la consecución de ésta". Esperanza Najar Moreno, Derecho a la verdad y justicia transicional en el marco de aplicación de la Ley de Justicia y Paz (Bogotá: Grupo Editorial Ibáñez, 
Empero, las transiciones políticas de los regímenes autoritarios, autocráticos y dictatoriales hacia modelos democráticos institucionales han revelado múltiples casos de vulneración de las garantías humanas individuales y colectivas, lo que, dentro de la progresiva implementación del Derecho Internacional de los Derechos Humanos, no deja de sorprender cuando es cada vez mayor el afán por fortalecer modelos de Estados sociales de Derecho, en donde se tiene claro que lo primordial es la defensa, protección y promoción de los derechos fundamentales de las personas, también como reacción a las crisis advertidas en aquellos regímenes acráticos.

No obstante haber sido revelados casos ilustrativos de vejámenes y violaciones a los Derechos Humanos cometidos en el marco de regímenes totalitarios o de difíciles bases democráticas sólidas, es notorio y preocupante el fenómeno de la violación a tales garantías en sistemas que, aun cuando asumen estos prototipos, han quedado cortos en cuanto a su respeto y promoción, bajo prácticas de guerra sucia y terrorismo de Estado, que no necesariamente exigen que sus autores tengan o hayan tenido la calidad de dictadores para convertirse en agentes victimarios.

Resulta riesgoso pretender condicionar solo a la voluntad política de los Gobiernos de turno el problema de la vulneración de los derechos fundamentales, pues a las múltiples causas de origen político deben sumarse situaciones sociales y económicas, como la desigualdad social, la pobreza estructural de los Estados, las persecuciones, los conflictos armados internos, los riesgos y las amenazas de conflictos internacionales y la proliferación de actores nacionales y extranjeros que se convierten en protagonistas de atentados contra los derechos humanos, entre otras causas. Sin embargo, como resultado de presiones sociales, los estándares internacionales en materia de protección, promoción y defensa de los derechos humanos, han llevado a considerar a los Estados como principales, mas no únicos, agentes responsables en el tema de las violaciones a derechos fundamentales,

2009), 15. Desde luego, esta concepción de la verdad, no como valor indeterminado sino como presupuesto exigible del Estado en cuanto a medidas no pecuniarias de reparación, forma parte de una serie de categorías adicionales y complementarias que, por su misma naturaleza y condición, se acercan a la construcción de una teoría de la justicia para las víctimas, con componentes que no solo comprometen económicamente la responsabilidad de los Estados, sino que también revelan las transformaciones históricas, políticas y sociales de las fundamentaciones políticas de las sociedades, que se comprometen cada vez más con el discurso de los derechos humanos y que, en consecuencia, exigen mayor compromiso de los Estados en esclarecimiento de hechos, revelación de verdades jurídicas, procesales y materiales y reconocimiento de daños causados en forma integral, aun cuando continúen reproduciéndose situaciones que no garanticen por completo la dignidad humana de las víctimas. En tales condiciones, al hablar de Estado, ya no se debe limitar la responsabilidad a los agentes directos que causaron las violaciones sistemáticas a los derechos humanos, sino al conjunto en sí de la institucionalidad estatal, la cual deberá asumir la responsabilidad de recomponer a la sociedad en todas las dimensiones posibles, lo que incluye aspectos tanto económicos como políticos y normativos. 
con el entendido que la noción de soberanía y omnipotencia del Estado se ha ido decantando históricamente y ha dado paso a la imagen de un sistema universal de protección a los derechos humanos.

\section{El caso colombiano ante los postulados de justicia transicional}

A propósito de los discursos aplicables al caso colombiano sobre el tema de justicia transicional, surgen múltiples interrogantes acerca de la necesidad, cada vez más vinculante, de estrechar los lazos entre estas formas y componentes de justicia y la obligación que asiste al Estado colombiano de adoptar políticas públicas integrales en materia de reparación a víctimas, la cual no puede ser vista solo en perspectiva de aplicación del principio de la solidaridad propio del Estado social de Derecho, sino como una obligación jurídica cada vez más imperante y vinculante, a la luz de los instrumentos internacionales de derechos humanos en materia de búsqueda constante de la materialización efectiva del derecho a la justicia y de la respuesta obligada por la violación de principios y normas internacionales de protección a los derechos fundamentales de los individuos. ${ }^{13}$

Podría pensarse que la acepción "justicia transicional" no resulta aplicable al caso colombiano, pues se ha dado casi por un hecho cierto que tal término obedece a un fenómeno jurídico, social y político que surgió como reacción a sistemas de permanentes violaciones de los derechos humanos, en particular, vinculados a regímenes totalitarios o dictatoriales. La primera impresión que se obtiene al hablar de justicia transicional en Colombia es la del rechazo, toda vez que, al menos en teoría, Colombia no ha sufrido tradiciones dictatoriales ni autoritarias durante

13 Respecto a la relación de los derechos a la verdad, la justicia y la reparación, dentro del contexto colombiano a propósito de las evoluciones sociales y en especial, de la puesta sobre la mesa de las discusiones sobre las necesidades de un proceso de paz y de la negociación con los grupos armados que han subsistido en las últimas cinco décadas en nuestro país, la Comisión de Seguimiento a la Política Pública sobre Desplazamiento Forzado señaló que "se requiere tener en cuenta que existe una interdependencia conceptual y operativa entre los derechos a la verdad, la justicia y la reparación, de tal manera que éstos forman parte de un todo al cual debe responder la política pública de manera integral, ya que cada uno de ellos obedece a la finalidad de desagraviar a las víctimas, conforme a la jurisprudencia de la Corte IDH. Es importante señalar que, no obstante que cada uno de estos derechos tiene una identidad propia que corresponde sólo a uno de los componentes de la política pública, ellos se encuentran interrelacionados, de tal forma que las medidas que se contemplen para la satisfacción de uno de éstos no pueden entenderse, diseñarse e implementarse de manera autónoma respecto de los derechos restantes". Luis Jorge Garay (dir.), Instituir una política integral de Verdad, Justicia y Reparación (Bogotá: Comisión de seguimiento a la política pública sobre desplazamiento forzado, Consultoría para los Derechos Humanos y el Desplazamiento [Codhes], 2011), 75-76. 
décadas. Es más, Colombia se ha preciado de poseer históricamente "la democracia más sólida de América Latina”, al ser el modelo de un sistema democrático de voto popular por excelencia. Es, tal vez, el país más democrático de América Latina, de donde deviene en un despropósito traer a este medio un concepto más bien vinculado a sistemas de endeble democracia, como sí ha sucedido en otros Estados en donde los períodos de democracia han sido escasos y, en su lugar, se han visto fortalecidos los ejercicios dictatoriales del poder.

Colombia no puede suponerse como un modelo propiamente democrático, a pesar de la ausencia de dictadores civiles o militares en la primera magistratura del poder público, pues las diferentes prácticas vividas en tiempos en los que la democracia bipartidista que imperó en el país dan cuenta de un sistema que reclamaba a gritos la salida hacia un modelo transicional de justicia.

La permanente adopción en Colombia de medidas institucionales como las constantes declaraciones de estados de sitio o de excepción, el incremento del poder militar aun para investigar y juzgar a los civiles, las políticas de guerra sucia del Estado, el uso de prácticas ilícitas como las ejecuciones extrajudiciales, las desapariciones forzadas o las torturas por parte de las fuerzas de seguridad del Estado, la eliminación de los opositores mediante la ejecución sistemática de los dirigentes de partidos disidentes, el exilio forzoso al que han sido sometidos múltiples opositores, la detención arbitraria y el juzgamiento sin pruebas o la adopción de instrumentos normativos usados como pretexto para combatir la inseguridad o el llamado "terrorismo" (estatutos o leyes de seguridad) que han llevado en Colombia a la restricción y negación de muchos derechos ciudadanos, entre muchos otros ejemplos históricos de la realidad nacional, distan bastante de las prácticas que se esperarían de un modelo estatal democrático.

Por el contrario, tales ejercicios de poder evidenciados en Colombia se han acercado más a prácticas autoritarias propias de los regímenes dictatoriales, incluso sin necesidad de la detentación del poder por parte de figuras militares, hechos que han demostrado de manera fehaciente la existencia de usanzas extremas de coerción de derechos fundamentales, en perjuicio del individuo y en defensa de regímenes que se han aprestado más hacia la dictadura de corte civil, lo que permite cuestionar si en realidad existe una democracia participativa y abierta, frente a los reales círculos del poder en Colombia, más allá de los grupos económicos y las familias que han ostentado el poder. ${ }^{14}$

14 En estas condiciones, cabe señalar que la sola ostentación de una sociedad electoralmente activa no es por sí misma garantía de una institucionalización y materialización real de la democracia y mucho menos en períodos 
El hecho de que Colombia se haya caracterizado por el voto como mecanismo por excelencia para elegir a sus gobernantes, habla de un modelo más o menos democrático, en comparación con regímenes militares como Argentina, Chile, Paraguay, Brasil o Guatemala o de dictaduras civiles como la del caso uruguayo, todas ellas caracterizadas por la negación de los derechos humanos y de la participación política para la elección de sus dirigentes. ¿Cómo hablar de la necesidad de una transición en un modelo democrático por excelencia, cuando una sociedad como la colombiana no necesitaría, por lo menos desde la teoría política, de una mutación de un Estado irregular hacia una sociedad transicional? La realidad de un conflicto armado interno reproducido por varias décadas habla de otra clase de realidades.

La justicia transicional aplicable al caso colombiano tiene que analizarse más allá de los simples tránsitos (de donde proviene su nombre) de regímenes totalitarios a democráticos, entendida como un mecanismo de búsqueda y aplicación de justicia, diferente al clásico sistema de justicia retributiva, es una perspectiva a mediano y largo plazo, que no solo busca sanar las heridas de estas transiciones políticas, sino también contribuir a conocer la necesidad de las víctimas, a asumir la obligación estatal de reparación integral y a proteger del olvido y de la impunidad la memoria colectiva en casos de violaciones sistemáticas a los derechos humanos. ${ }^{15}$

\footnotetext{
históricos en que el Estado colombiano ha tenido que afrontar un conflicto armado interno no declarado, que ha servido para generar el estado de masivas violaciones a los Derechos Humanos, que hoy por hoy demandan la necesidad social de buscar salidas y alternativas a las crisis sociales vividas. En este contexto deben ser analizados los derechos particulares de las víctimas como consecuencia de situaciones anormales de vulneración, producto de un conflicto o de una situación anormal, el llamado "estado de cosas inconstitucional" de que trató la Corte Constitucional en Sentencia T-025 del 22 de enero de 2004, M. P. Manuel José Cepeda Espinosa concepto que se introdujo desde 1997 en Sentencia SU-559, con ponencia de Eduardo Cifuentes Muñoz y que ha variado hasta llegar a ser definido como aquella suerte de circunstancias en las que "1) se presenta una repetida violación de derechos fundamentales de muchas personas que pueden entonces recurrir a la acción de tutela para obtener la defensa de sus derechos y colmar así los despachos judiciales, y 2) cuando la causa de esa vulneración no es imputable únicamente a la autoridad demandada, sino que reposa en factores estructurales". Corte Constitucional, Sentencia SU-090 de 2000, M. P. Eduardo Cifuentes Muñoz.

15 Al respecto, una acertada crítica se puede encontrar en Rodrigo Uprimny Yepes, en donde se habla del modelo colombiano de una guerra no declarada; en ella, las permanentes violaciones a los derechos humanos ha sido producto de diferentes acciones y propiciada por diferentes agentes, que continúan generando un clima propicio para reclamar la participación social y política de los actores del conflicto, pero también los derechos de las víctimas, eje central de un modelo de justicia restaurativa que se corresponda con los postulados del Estado social de Derecho, contrario desde todo punto de vista, tanto en su acepción política como en su esencia dinámica al estado de cosas inconstitucional a que se ha referido reiteradamente la Corte Constitucional colombiana. Rodrigo Uprimny Yepes, María Paula Saffon Sanín, Catalina Botero Marino y Esteban Restrepo Saldarriaga, ¿justicia transicional sin transición? Verdad, justicia y reparación para Colombia (Bogotá: Dejusticia, 2006).
} 
El problema de la justicia transicional en Colombia presenta, entonces, la particularidad de no haber sido creada en un contexto de una salida democrática a regímenes totalitarios. La realidad colombiana se ha caracterizado por la existencia de uno de los conflictos armados internos de mayor duración en el mundo, que durante mucho tiempo no fue reconocido por las instancias transitorias de poder político, conflicto que, en gran medida, ha sido producto de la marcada desigualdad social alimentada con fenómenos como el narcotráfico, la guerra de guerrillas o la corrupción estructural y ha perpetrado una victimización hacia amplios sectores sociales, ante la pasiva y a veces cómplice mirada del Estado.

A la proliferación de la guerra de guerrillas de grupos armados revolucionarios de extracto popular y campesino, como las Fuerzas Armadas Revolucionarias de Colombia (FARC), el Movimiento Indigenista Quintín Lame, el Ejército de Liberación Nacional (ELN) o el Ejército Popular de Liberación (EPL), además de grupos como la Autodefensa Obrera (ADO) y el Movimiento 19 de Abril (M-19), que plantearon la revolución armada como alternativa política de inclusión social y de reconstrucción de un nuevo modelo de Estado, se sumaron también grupos de autodefensas campesinas y movimientos paraestatales, ejércitos paramilitares y escuadrones de la muerte, financiados por terratenientes, ganaderos y narcotraficantes y, en muchas ocasiones, por personal activo o retirado de las Fuerzas Armadas institucionales, lo que recrudeció el conflicto armado interno que década tras década ha permeado todas las instituciones sociales, económicas y políticas del país.

Durante las últimas cinco décadas, este conflicto armado de carácter multilateral ha generado en Colombia un caldo de cultivo propicio para la desestabilización de las instituciones realmente democráticas y ha causado gran cantidad de víctimas de diversos sectores de la población, muchas de las cuales se han causado por la acción u omisión directa de los agentes estatales y otras por parte de los ejércitos irregulares y los demás actores del conflicto, lo que desdice de la democracia formal que las instituciones han pretendido sustentar en diversos escenarios supranacionales.

En tal sentido, una de las críticas más frecuentes al modelo de democracia colombiana es que la construcción de una forma de Estado de Derecho anclado en principios suprajurídicos no es suficiente, cuando las condiciones reales de las personas que habitan el territorio nacional distan de las garantías señaladas en las normas y, en especial, cuando las condiciones materiales inmediatas, tanto las ordinarias como las que han terminado deterioradas con ocasión de una guerra no declarada, han estado marcadas por el fenómeno de la victimización de amplias capas sociales y la 
vulneración de derechos fundamentales de millones de personas, a pesar de que la figura del Estado de Derecho haya sido una constante en el régimen político de las instituciones colombianas.

Al ver este tipo de realidades, podría señalarse que la necesidad de una política pública de reparación a las víctimas en Colombia no debe entenderse como un mero fenómeno jurídico que responde a olas progresistas sociales de otras latitudes que se imponen en el país. La reparación a las víctimas, como fenómeno jurídico, social y político es también una respuesta de la misma sociedad colombiana ante el creciente destape de situaciones críticas en materia de violaciones sistemáticas a los derechos humanos y comporta en sí misma la exigibilidad de contar con escenarios adecuados para su implementación y sostenibilidad.

Entonces, si se acepta que las violaciones a los derechos humanos en Colombia no han sido generadas en el marco de un régimen dictatorial, sino que han sido producto de una guerra que ha subsistido durante más de cincuenta años (en la que la responsabilidad es compartida por diferentes agentes, frente a la comisión de crímenes de diversa naturaleza, del despojo de la tierra y el consecuente fenómeno del desplazamiento forzado, de la persecución genocida sobre poblaciones o grupos ideológicos o de la participación estatal en ejecuciones extrajudiciales, torturas, desapariciones forzadas y otros crímenes de similar gravedad a la luz de las normas de Derecho Internacional de los Derechos Humanos), es necesario aceptar también que es urgente la adopción de medidas institucionales para procurar la reconstrucción social y la recomposición, una vez se generen las condiciones de cese inminente del conflicto, hacia una paz estable y duradera.

Desde esta perspectiva, habrán de reconocerse dos elementos transversales: por un lado, que la justicia transicional es un fenómeno que surge como reacción natural de las sociedades contemporáneas a graves períodos de vulneración de derechos humanos y graves crisis humanitarias institucionales, que evoluciona a partir de la búsqueda de soluciones reales y materiales en contra de la impunidad con la que variados Gobiernos garantizaron la tranquilidad mediante leyes de perdón y olvido o de punto final, leyes que, con el paso de los tiempos, han venido siendo revaluadas y, en muchos casos, han perdido su validez y eficacia, por la altísima presión de múltiples sectores de la sociedad civil. Por otro lado, si se le entiende como una transformación social y política de reconstrucción del tejido social y humano, la justicia transicional debe operar como respuesta a la búsqueda material de la 
justicia como valor fundante de esa sociedad en evolución, tras superar buena parte de la situación de crisis estructural que ha causado el deterioro del cual se deriva.

La primera necesidad que reclama esta sociedad civil es el derecho innegociable a conocer la verdad, punto de partida para intentar cualquier acuerdo o negociación entre víctimas y victimarios. La verdad histórica, no solo la procesal o judicial, constituye el elemento sociológico y político de más alta trascendencia en cuanto a procesos transicionales, por su significación de alto impacto internacional y porque, en sí mismo, comporta el máximo esfuerzo de reclamar a los círculos de poder por el respeto de las libertades y garantías individuales, inherentes al concepto de dignidad humana, eje central del cual depende todo el discurso de los derechos humanos.

Si los derechos de las víctimas se entienden como derechos fundamentales que deben ser reivindicados por una afectación sensible y grave, derivada de la conducta activa o pasiva del Estado en el marco de un conflicto armado interno como el que ha soportado Colombia durante ya más de cinco décadas de permanente guerra entre múltiples actores, lo cierto es que a partir de la Constitución Política de 1991 el Estado debió haber adquirido una responsabilidad mayor sobre las víctimas y no esperar a que el recrudecimiento de la guerra obligara, bajo presiones internacionales, a que se hablara de la urgencia de repararlas y de reconocer los derechos que venían siendo afectados de tiempo atrás.

Las normas relacionadas con la aceptación de un conflicto armado no declarado en Colombia, así como las que se relacionan con las obligaciones estatales frente a una reparación integral a las víctimas reconocidas del conflicto y la obligación de atender con especial protección a esta clase de grupos poblacionales, como la Ley 1448 de 2011, resultan ser una muestra tardía de la aceptación del Estado colombiano de su participación en el conflicto, de su responsabilidad en la violación de derechos fundamentales, de la reproducción del estado de cosas inconstitucional que se soporta en el país y del desconocimiento de garantías jurídicas de primer orden para todos sus habitantes.

\section{Presupuestos axiológicos}

Esta suerte de garantías a la que se ha hecho referencia, requeriría para el caso colombiano ser optimizada y traducida en términos de eficacia y eficiencia por parte de las instituciones estatales con plena participación de la sociedad civil, dado que 
en la misma Carta Política se encuentra consagrado un Estado social de Derecho y que, más allá de la solidaridad que le compete, y que exige en términos de ayuda y socorro mutuos, debe poner sus instituciones jurídicas, políticas y administrativas al servicio y la garantía de los derechos fundamentales, con especial atención a esas víctimas a quienes, independientemente de un modelo transicional, les interesa saber qué pasará con sus justas reclamaciones y cómo podrán recuperar en algo todo lo que el conflicto interno les ha arrebatado.

En este contexto, los derechos de las víctimas, como unos derechos de especial categoría, no pueden dejar de concebirse dentro de la idea de un Estado social de Derecho, como criterios jurídicos que merecen ser atendidos y respecto a los cuales el Estado, en aras de una verdadera transición jurídica y política, debe garantizar su materialización efectiva. Para el escenario colombiano, las normas de transición deben contemplar elementos sociales, jurídicos y políticos capaces de traducirse en medidas de política pública tanto para la atención y la asistencia por parte del Estado como para atender la obligación jurídica ante el Derecho Internacional de reparar integralmente, en términos de restitución, indemnización, memoria colectiva, garantías de no repetición y demás elementos contemplados a la luz de los principios y normas internacionales, ${ }^{16}$ dado que desconocer estas categorías jurídicas implicaría nada menos que la denegación manifiesta de la justicia material.

De la misma forma, no es necesario un panorama de forzosa intervención judicial para que la necesidad de reparar a las víctimas se haga exigible, en ambientes sociales y políticos que revelan la necesidad de soportar cambios transicionales como producto o reacción social a graves crisis humanitarias. Si bien los mecanismos

16 El derecho fundamental a la reparación integral tiene por fin la promoción de la justicia, la materialización de las condiciones objetivas reales que se han visto afectadas por el hecho causante de la violación y la recuperación de las condiciones afectadas por ellos, para tratar de responder a las expectativas legítimas de las víctimas que se han conculcado por eventos que no deberían haberse presentado en situaciones de normalidad, dentro de un contexto democrático y participativo. Huertas Díaz, "Los derechos de las víctimas de las violaciones a los derechos humanos", 133. De la misma forma, y conforme a la doctrina internacional, el concepto de reparación comprende, según Mejía Gómez "la garantía de los derechos y libertades conculcados, reposición de las cosas al estado en que se encontraban, alivio o restauración de los bienes jurídicos injustamente afectados (tomando en cuenta las características de éstos), reducción de las consecuencias lesivas o peligrosas, compensación por los efectos que sea imposible cancelar o excluir de otra manera y evitación de reiteraciones" y asimismo comprende los diferentes instrumentos, medidas, formas e instituciones con los que cuenta un Estado para garantizar la protección de los derechos fundamentales conculcados, además de aquellos instrumentos implementados para prevenir y recuperar las condiciones dignas mínimas que se han afectado con ocasión de graves violaciones a derechos humanos, dentro de las cuales, las medidas de contenido económico juegan un importante rol, en relación con la satisfacción de necesidades básicas afectadas. Camilo Mejía Gómez, La reparación integral con énfasis en las medidas de reparación no pecuniarias en el Sistema Interamericano de Derechos Humanos (Bogotá: Universidad Externado de Colombia, 2005), 15. 
e instrumentos judiciales predispuestos por el legislador en materia de reconocimiento de derechos y garantías para su ejercicio se transforman en la herramienta más precisa, no es dable desconocer que se llega a ellos como resultado de las fuertes y masivas intervenciones y presiones de los grupos y colectivos sociales que, en el caso colombiano, solo requerirían haberse visto afectadas por el conflicto armado interno y por la permanencia del estado de sitio, para sentirse legitimados al momento de reclamar la implementación de una política pública de reparación dentro de los límites de la justicia transicional.

Mas, para hablar de la implementación y aplicación de un sistema o un modelo de justicia transicional en Colombia, es necesario partir de la aceptación de una serie de acuerdos políticos, sociales y jurídicos entre los diferentes actores involucrados, esto es Estado, guerrilla, carteles del narcotráfico, paramilitares, autodefensas y sociedad civil, acuerdo en el que el derecho a la verdad debe acompañarse de diferentes instrumentos para su realización y materialización, sin que con ello se ponga en riesgo el principio de la obligación de reparación a las víctimas.

En este sentido no es posible concebir un proceso transicional de justicia si no se focaliza a las víctimas del conflicto como destinatarios últimos de la labor reparadora del Estado, de quien dependen las estrategias fundamentales tanto judiciales como administrativas, legislativas y colectivas, para enfrentar y superar el pasado violento padecido en Colombia, sin comprometer la condición ni el derecho de las víctimas. En otras palabras, aunque de cierto modo la aplicación de un modelo de justicia transicional implica un acercamiento entre la justicia penal clásica y ciertos modelos de justicia negociada, lo que no se debe permitir es que con este tipo de sistemas se desconozca la obligación fundamental del Estado como principal responsable en materia de derechos humanos.

Dentro de los elementos principales de la justicia transicional se identifican los derechos a la verdad, la reparación, la justicia material, la implementación de reformas institucionales y la recuperación y conservación de la memoria histórica. En este panorama, se debe entender que la justicia penal clásica es insuficiente, cuando se ha pasado por graves períodos sociales e históricos en donde se encuentran comprometidos los derechos humanos por graves riesgos, amenazas o situaciones de violaciones sistemáticas, que, en el caso colombiano, obedecen a guerras producto del empoderamiento de vastas zonas geográficas por parte de grupos irregulares, como a la irrupción del fenómeno del narcotráfico, con todas las consecuencias que ya se conocen. 
En un modelo de justicia transicional para Colombia, el Estado debe asumir un papel de actor principal, capaz de fomentar los mecanismos para su aplicación, en donde él sea garante de tales derechos, como producto de la superación del conflicto armado interno y de las causas estructurales que lo han perpetuado. Asimismo, debe participar de manera activa en los procesos de construcción y reconstrucción social y en los procesos de recuperación de la memoria histórica colectiva, que van más allá de la memoria judicial. En su papel de garante de una transición social, política y jurídica, el Estado está llamado a ser el principal agente en procesos de reparación y reconciliación. Todos los elementos indicados deben estar conectados para que se pueda entender un concepto más ajustado de la justicia transicional. Deben existir garantías reales de la aplicación de medidas efectivas de reparación, que se hacen más efectivas si hay verdad judicial, además de verdad histórica y memoria colectiva, como una garantía de no repetición. ${ }^{17}$

17 Huertas destaca como elementos propios de la reparación, como categoría jurídica internacional, los siguientes, los cuales también tienen respaldo en los Principios y Directrices Básicos: 1. La restitución (restitutio in integrum): es la figura jurídica conforme a la cual se procura reponer una situación a su estado original o al restablecimiento de las situaciones existentes antes de perpetrada la violación a derechos fundamentales, como producto del desconocimiento de las normas de derechos humanos o Derecho Internacional Humanitario. Este elemento está compuesto por categorías como "el restablecimiento de la libertad, el disfrute de los derechos humanos, la identidad, la vida familiar y la ciudadanía, el regreso a su lugar de residencia, la reintegración en su empleo y la devolución de sus bienes", lo que se vincula al ejercicio de los derechos civiles y políticos, así como al uso de las garantías que subsistían a la situación que causó el perjuicio. Como se observa, esta obligación existe, en sí misma, como garantía fundamental de la persona humana. Mas hablar de garantías como restablecimiento de derechos políticos, libertades fundamentales, disfrute de derechos de participación, retornos a lugares de residencia, reintegración de empleos perdidos y devolución de bienes, entre otras figuras, están contemplando implícitamente las garantías esenciales para obtener la satisfacción de las necesidades humanas básicas. 2. La rehabilitación: se trata de una categoría jurídica conforme a la cual se procura que las víctimas afectadas por graves violaciones a los derechos humanos recuperen ciertos servicios y atenciones con los cuales se continúan satisfaciendo necesidades básicas, pero esta vez asociadas con los llamados "derechos sociales o colectivos", como la obligación del Estado de atender médica y sicológicamente a las personas que han soportado esas cargas extraordinarias que no estaban obligadas a sufrir. En esta perspectiva, tal componente exige una participación más activa del Estado, en tanto se le exige como organización política y social, que cubra ciertas necesidades que subsisten en todas las sociedades, pero esta vez asume a su propia costa los gastos derivados de su sostenimiento, en tanto que para el resto de la población estos mismos servicios son garantizados indistintamente de su condición de víctimas, mediante su vinculación a un sistema general de seguridad social, casi siempre alimentado económicamente en forma mixta por el Estado como por los particulares. La Rehabilitación, como componente del derecho fundamental a la reparación integral, busca que las personas afectadas traten de recomponer el rumbo social de sus vidas, por medio de la obtención de servicios jurídicos y sociales a los que, por lo general, no tendrían acceso de no haberse visto afectados por violaciones a sus derechos fundamentales; esto advierte acerca de su condición de medios de satisfacción de necesidades básicas lesionadas con ocasión de la violación o del menoscabo sufridos. 3. La indemnización: conforme al Principio No. 20 del Instrumento internacional en comento, la indemnización jurídica es el pago económico que se cuantifica como resultado de un perjuicio o violación a derechos fundamentales evaluables económicamente, que comprenden tanto el lucro cesante como el daño emergente, en casos de daños físicos o mentales, perjuicios actuales o futuros y que correspondan a eventos en donde se afecten oportunidades, ingresos, posibilidades de subsistencia o gastos sufragados por la víctima, cuando su erogación correspondería al causante del perjuicio. Esta figura jurídica debe ser apropiada y proporcional a la gravedad del daño 
La base de la aceptación de una necesidad social y política de concebir el derecho a la reparación como un derecho social fundamental radica en su utilidad práctica; es de esa necesidad humana y colectiva de blindar a la sociedad con herramientas e instrumentos idóneos que permitan luchar contra toda forma de impunidad que nace la obligación de crear puentes de reconciliación entre los actores armados. Para ello no se necesita transmutar la dictadura en democracia, porque la realidad es que en múltiples regímenes democráticos también se han presentado sistemáticas violaciones a los derechos humanos, ya por causas exógenas al mismo Estado, bien porque este influye de modo decisivo en este tipo de crisis humanas.

Ahora bien, no es posible hablar de procesos de reconstrucción social sin que haya condiciones materiales de transformación de los modelos políticos, sociales y jurídicos, dependientes de situaciones objetivas que implican alteración positiva sustancial de las realidades humanas. Por lo anterior, no es dable hablar de una justicia transicional, en estricto sentido, en un país en el que no se ha producido una transición real, material ni social de un estado de cosas a otro ni en una sociedad en la que no se han desarrollado las bases para hablar de una transformación social, económica y política, puesto que es esa superación de condiciones las que obligan a reconstruir el escenario normativo de la nueva sociedad, de cara a los retos del futuro.

Cabe preguntarse si es pertinente la implementación inmediata en Colombia de un espectro normativo de carácter transicional y si sus componentes jurídicos están fundados con solidez en procesos sociales de recomposición, toda vez que en nuestro país, a pesar de los avances jurídicos formales del Derecho en los últimos años, el estado de cosas inconstitucional en el que se han producido las violaciones sistemáticas a los derechos humanos todavía está latente y aún se reproducen condiciones estructurales de exclusión social, de pobreza, de marginación y de desigualdad, insumos para la continuidad del conflicto armado, amén de que dicho conflicto sigue latente y los pocos avances en materia de diálogos de paz que se han intentado en los últimos meses van camino a la incertidumbre, no solo por la

o perjuicio causado y a las circunstancias en que se produjo el evento dañoso, existiendo para ello criterios de evaluación y ponderación económicos, como la pérdida de capacidad económica, los gastos asumidos por las víctimas o lo dejado de percibir por ellas, como consecuencia de graves violaciones e infracciones de las normas internacionales de derechos humanos y Derecho Internacional Humanitario, y, para efectos del presente análisis, como consecuencia a las afectaciones esenciales para garantizar la supervivencia humana en condiciones dignas. 4. La satisfacción: que corresponde a una serie de elementos con los cuales se pueda garantizar que la víctima va a sentirse plenamente reparada, pues aunque las medidas relacionadas con aspectos económicos sean las prioritarias, existen otros aspectos que rodean la integralidad de la dignidad humana que no se compensan con dinero, por más altas que sean las sumas comprometidas. Huertas Díaz, "Los derechos de las víctimas de las violaciones a los derechos humanos", 134. 
alteración de las agendas programáticas, sino también por la falta de inclusión de todos los actores armados, sociales y políticos en las mesas de diálogo.

Pese al entramado de buenas intenciones que se han discutido en el caso colombiano, lo cierto es que las pocas políticas públicas que se han pensado en materia de un modelo de reparación de víctimas, bajo el reconocimiento de una necesidad colectiva, han demostrado que el Estado colombiano aún desconoce su condición de responsable y garante de los derechos humanos, lo que ha generado críticas provenientes de diferentes sectores y obligan a concluir que el sistema de justicia transicional aún no ha sido entendido ni aplicado correctamente en nuestro país. ${ }^{18}$ La implementación de un amplio conjunto de normas por sí misma resulta insuficiente e insatisfactoria, a la luz del Derecho Internacional y a los ojos de las víctimas.

Ahora bien, en tal panorama, resulta necesario señalar que no es suficiente con estimular las amplias movilizaciones sociales si estas no cuentan con mecanismos reales de incidencia política, es decir, con representación en las corporaciones públicas, en el Congreso, en las altas instancias de poder y en los escenarios decisorios de la vida política y social del país. Es preciso continuar revistiendo este tipo de fenómenos, aunque es cierto que las movilizaciones políticas deben estar acompañadas de instrumentos jurídicos internos e internacionales de alta trascendencia que impidan la ocurrencia de situaciones como las sucedidas en otros espacios geográficos, en donde ciertas vías democráticas han desfigurado los derechos de las víctimas por medio de los mecanismos de perdón y olvido que jamás debieron ser permitidas y que pueden servir de ejemplo muy ilustrativo de lo que no se debería reproducir en el marco del conflicto colombiano, a propósito de los procesos de "reconciliación" que se predican en nuestro país.

18 Luego de examinar las condiciones reales de muchos sectores de la población civil, afectada por el conflicto, el Consejo realizó una primera conclusión al analizar los resultados inmediatos del marco de Justicia Transicional que se produjo a partir de la Ley de Justicia y Paz, señalando: "En esta perspectiva y teniendo claras las consecuencias del modelo de desmovilización y de reparación que propone la Ley de Justicia y Paz que el Gobierno Nacional reivindica, se ha de anotar que el texto del plan parte de nociones generales del derecho a la verdad, a la justicia y a la reparación, mas no se pronuncia acerca de aspectos fundamentales como las garantías para que las víctimas accedan a la justicia, los instrumentos esenciales para que la responsabilidad de los agentes estatales sea establecida y asumida y la política en materia de alternatividad penal. Tampoco considera el enfoque diferencial que ha de tener una justicia transicional, con el objetivo de que ésta reconozca el impacto diferenciado del conflicto armado en diversas poblaciones, como es el caso de las mujeres, en aras de proponer fórmulas adecuadas en consonancia con esa visión para el establecimiento de la verdad, la consecución de la justicia y la posibilidad de una reparación que no sea meramente simbólica". Consejo Nacional de Planeación, Retos del Plan Nacional de Desarrollo 2006-2010: Estado Comunitario: desarrollo para todos. Una mirada desde la Sociedad Civil (Bogotá: Milenio Editores, 2007), 107. 
En otras palabras, no se podría formular la implementación de una política legislativa y pública de justicia transicional si no se van a establecer condiciones reales de transformación social que representen cambios estructurales en la vida social, política y económica del Estado y si no se van a garantizar medios para hacer efectiva la justicia social material pregonada desde la filosofía dogmática del Estado social de Derecho, pues de lo contrario, se abordaría una transición sin haber salido del estado inconstitucional de crisis social y humanitaria que ha ido de la mano del conflicto mismo durante las últimas décadas en Colombia.

Entonces, una salida política y negociada al conflicto que abra las puertas a verdaderos procesos de reconciliación y que, conlleve a la necesidad real de construir una justicia transicional en nuestro medio, requiere de una plataforma institucional previa que trascienda de las simples reformas institucionales legislativas. La adopción de instrumentos jurídicos y políticos orientados al reconocimiento de la verdad histórica y material, como elemento esencial de la reparación, obligación jurídica y moral del Estado, se hace más necesaria en sistemas como el colombiano, en el cual la reparación ha sido entendida desde las altas esferas del poder ejecutivo como una extensión del principio de solidaridad; esto desconoce que el deber de reparar a las víctimas de las graves violaciones a los derechos humanos no emana del asistencialismo benefactor del Estado, sino de su responsabilidad por participar, de manera activa o pasiva en esas violaciones sistemáticas y como consecuencia directa de las violaciones a los principios jurídicos universalmente aceptados y reconocidos, además de que constituye una obligación moral de recordar a las víctimas, a los hechos acaecidos y a la necesidad de reconciliación social. Tal obligación se convierte en componente de la justicia material propia del Estado social de Derecho. ${ }^{19}$

Las experiencias de demorados y dolorosos procesos de justicia transicional como en Argentina o Uruguay, han demostrado que la fragilidad institucional y la debilidad de los Gobiernos de transición son caldo de cultivo para amparar formas múltiples de impunidad, aun a pesar de las amplias movilizaciones sociales. No basta la adecuación del Derecho interno a los hechos. Ni con ampliar el espectro de la denuncia y la reclamación de reivindicaciones sociales. Se precisa con demasiada urgencia, que las fuerzas políticas reunidas en el Congreso de la República entiendan que, dentro de su papel de representación popular, asiste el deber de acompañar a las víctimas de la violencia y del conflicto armado.

19 Paula Ayala Rodríguez, La reparación integral como forma de cumplir con la obligación moral de recordar (Bogotá: Ediciones Uniandes, 2005), 20-21. 
Acompañar a las víctimas no es solo invitarlos a las ponencias y debates sobre la Ley de Víctimas, sino también reconocer el derecho colectivo que les asiste a conocer la verdad como un derecho humano fundamental, así no encuentre expresión concreta en la Constitución Política de 1991, dado que el presupuesto de la dignidad es el que encierra en sí mismo el derecho al reconocimiento del ser humano como destinatario de la protección del Estado. Dentro de esa protección se debe fundamentar el derecho a la reparación integral por el daño causado — verdadera legitimación jurídica de la justicia transicional, vista como la integración jurídica, política, social y esencialmente humana - necesaria en un territorio como Colombia, fragmentado y fracturado por tantos años de convulsión y violencia social.

Los requerimientos de las víctimas en Colombia precisan medidas integrales de satisfacción y también que las políticas públicas en la materia formen parte de un espectro social y normativo adecuado, en el que la justicia transicional sea una salida digna a las condiciones de exclusión y victimización que se han reproducido históricamente por más de medio siglo en el país, puesto que las experiencias transicionales de los últimos años, en particular, la justicia derivada de la Ley 975 de 2005, llamada Ley de justicia y paz, han evidenciado la necesidad de recrear las condiciones de reconstrucción del tejido humano y social, en términos de superación del quebrantamiento de la institucionalidad jurídica y política vivida en Colombia.

\section{Conclusiones}

A manera de conclusiones preliminares, pues el objeto de estudio amerita muchos más análisis, puede señalarse que el recrudecimiento del conflicto interno, la expansión del poder de grupos armados ilegales, el fortalecimiento de ejércitos paraestatales y la constante pugna por la propiedad sobre vastas extensiones del territorio nacional, sumado a factores como la guerra derivada del tráfico de sustancias estupefacientes ilícitas o el incremento de la corrupción, fomentada en regiones con débil presencia institucional del Estado, han llevado a que sean múltiples los insumos que han alimentado la guerra y el conflicto no declarado en Colombia, a pesar de que cuenta con una de las más sólidas democracias formales del hemisferio, mito político que subsiste en gran parte por la continuidad de las elecciones populares y la ausencia de dictaduras de carácter civil o militar que significaran un totalitarismo similar al de regímenes como los del Cono Sur, en donde se experimentaron feroces dictaduras que aún hoy siguen dejando secuelas sociales en las generaciones posteriores a la instalación de la democracia. 
Son acertadas las críticas frecuentes que se han hecho al sistema social y político colombiano que señalan la debilidad institucional de una democracia formal amparada en la permanencia de estados de sitio o de excepción, propios de regímenes totalitarios, pero que proliferaron por décadas en nuestro país y que fortalecieron el conflicto insurgente, contrainsurgente y paramilitar que desde hace un buen tiempo han puesto a Colombia en la palestra internacional como uno de los lugares de mayor crisis en todo el mundo en cuanto a violaciones de derechos humanos y amenazas a las garantías y derechos fundamentales de las personas.

Así las cosas, se observa en el presente texto la idea clara de que a Colombia le urge la aplicación de un modelo de justicia transicional, entendida como un mecanismo político y jurídico óptimo para facilitar la integración social de una sociedad en fase de posconflicto, cuya búsqueda principal, además de conciliar las expectativas legítimas de las víctimas en materia de reparaciones integrales, sea esclarecer los problemas de impunidad y olvido que han caracterizado a los regímenes totalitarios y a las democracias desestabilizadas, en donde los movimientos sociales y las organizaciones de víctimas y de sus familiares han procurado mantener viva la memoria de los olvidados, aquellas víctimas de la violencia y del terrorismo estatal. ${ }^{20}$

20 Es importante tomar como referencia al respecto lo expresado por la Corte Constitucional en Sentencia C-1189 de 2008, en la que el máximo Tribunal hizo referencia a la exequibilidad de la Ley 975 de 2005, Ley de Justicia y Paz, tratándose de la incorporación de un modelo transicional real en el marco del conflicto armado, aunque el examen de constitucionalidad de la norma pareció más bien limitarse al contenido formal integral de una normatividad que a pesar de dejar inmensos vacíos, no fue el verdadero resultado de un proceso de integración social. En dicho pronunciamiento se destaca, de especial interés, lo que la Corte refirió sobre los alcances inmediatos de la Ley, en los siguientes términos: "La Corte ha relievado la importancia de los derechos a la verdad, la justicia y la reparación, que tienen un contenido propio y específico dentro de un contexto de justicia transicional, los cuales si bien no agotan el catálogo de derechos de las víctimas, constituyen la columna vertebral de tales garantías, resaltando además la cercanía y mutua dependencia existente entre estos tres conceptos, al señalar: "la verdad, la justicia y la reparación se erigen como bienes cardinales de toda sociedad que se funde en un orden justo y de pacífica convivencia, entre los cuales median relaciones de conexidad e interdependencia, de manera tal que: No es posible lograr la justicia sin la verdad y no es posible llegar a la reparación sin la justicia [...].

Como resultado de un extenso análisis la Corte destacó que la reparación: i) incluye todas las acciones necesarias y conducentes a hacer desaparecer, en la medida en que ello sea posible, los efectos del delito; ii) al igual que el concepto de víctima, tiene una dimensión tanto individual como colectiva; iii) no se agota en su perspectiva puramente económica, sino que tiene diversas manifestaciones tanto materiales como simbólicas y iv) es una responsabilidad que atañe principalmente a los perpetradores de los delitos que dan lugar a ella, pero también al Estado, particularmente en lo relacionado con algunos de sus componentes [...]. El derecho a la reparación en la ley de justicia y paz tiene un contenido propio, que se deriva del texto de su artículo $8^{\circ}$, norma que si bien no define el concepto de reparación, sí se refiere a los distintos tipos de prestaciones que ella engloba, al establecer: "El derecho de las víctimas a la reparación comprende las acciones que propendan por la restitución, indemnización, rehabilitación, satisfacción; y las garantías de no repetición de las conductas", observándose que no todos los componentes del concepto de reparación tienen contenido económico, siendo la rehabilitación uno de los aspectos que conforman el concepto de reparación, que se refiere a las acciones que buscan restablecer la salud de las víctimas, incluyendo tanto 
En tales condiciones, se debe reconocer que los propósitos o presupuestos axiológicos de la idea de justicia transicional aún están lejos de la visible realidad inmediata de nuestro país, porque las condiciones materiales en las que hoy se vive, no han variado sustancialmente de aquellas condiciones en las que se propició el conflicto armado, así como tampoco se han superado las condiciones de inequidad social y económica y exclusión social para grandes grupos poblacionales.

Hablar de justicia transicional en un país como Colombia, en donde el conflicto armado persiste, las instituciones democráticas siguen permeadas por mafias y grupos delincuenciales y se ha desconocido la dimensión integral de la justicia de transición en aspectos claves como la verdad, la memoria y la reparación, debido a la poca importancia dada a las víctimas, resulta bastante desafortunado ante el concierto jurídico internacional, a la luz de los estándares y principios universales del Derecho Internacional de los Derechos Humanos, toda vez que no es posible hablar de la existencia de una sociedad en transición, cuando aún no se ha salido de las condiciones materiales que dieron origen a la expedición de la norma y, en estricto sentido, no se ha hecho transición de un estado de guerra a una sociedad posconflicto.

Lo anterior quiere decir que, a pesar de que el discurso político y jurídico nacional se dirija a la novedad que supondría la instauración de una justicia transicional en Colombia, lo cierto es que la realidad demuestra que estamos lejos de un marco transicional, porque aún no hemos salido del conflicto, porque nuestras realidades políticas y sociales revelan que la guerra continúa y porque la voluntad política de nuestros dirigentes ha sido insuficiente respecto a la reconstrucción de un panorama apto para hablar de una reconciliación real entre los múltiples sujetos activos y pasivos de los delitos cometidos en el marco de la guerra.

Entonces, ies posible hablar en Colombia de una justicia transicional, entendida en su dimensión integral, a la luz de la normatividad vigente? La respuesta es que el término justicia de transición todavía está lejos de ser un verdadero escenario para esta imprescindible necesidad de la justicia, tanto a la luz de las disposiciones internacionales de derechos humanos como a la luz de los postulados esenciales del Estado social constitucional y democrático de Derecho, en especial si se analiza la

los aspectos puramente somáticos, como los relacionados con su bienestar emocional o su salud mental, aspectos igualmente necesarios para vivir y desarrollar una existencia digna; de allí que pueda aseverarse que todas las acciones de rehabilitación que se ejecuten dentro del marco de esta ley se consideren actos de reparación, pero no al contrario". 
realidad nacional desde los ojos de las víctimas, protagonistas reales de los contextos transicionales a los que se ha hecho referencia.

Mientras el estado de guerra se mantenga, el conflicto armado permanezca y se reproduzcan las mismas situaciones económicas, sociales y políticas en las que se han generado las condiciones de crisis humanitaria y la violación sistemática a los derechos humanos en Colombia, la implementación de un modelo de justicia transicional será solo una plataforma discursiva de difícil concreción que no se compadecerá de las realidades directas e inmediatas de una sociedad en crisis. Más aún, mientras no se concreten acuerdos reales y duraderos de paz, no será posible abordar temáticas y componentes de justicia transicional en Colombia, en donde se hagan aplicables las garantías propias del derecho a la reparación integral, en sus dimensiones de verdad, justicia, reparación, garantías de no repetición, recuperación de la memoria social e histórica y compromisos de reconstrucción del tejido social.

En síntesis, en las condiciones actuales de la realidad colombiana no se puede dejar de lado que la fórmula discursiva del Estado social y democrático de Derecho solo seguirá siendo un buen referente del marco normativo imperante, pero no necesariamente será un diagnóstico ni un reflejo de la realidad. Esto solo se logrará si se advierte que, más allá de las simples consecuencias jurídicas de ciertos hechos, subyacen derechos fundamentales que, al igual que las categorías jurídicas propias de cada ser humano, también están asociados con la reparación integral, aún por encima de los esquemas políticos institucionales que pretendan adquirir suficiente legitimidad sin lograrlo, pues para ello, el Estado social de Derecho deberá redoblar sus esfuerzos en la cobertura y satisfacción integral de las garantías humanas.

\section{Referencias}

Arango Rivadeneira, Rodolfo. Derechos Humanos como Limite a la Democracia: análisis de la Ley de Justicia y Paz. Bogotá: Norma, 2008.

Ayala Rodríguez, Paula. La reparación integral como forma de cumplir con la obligación moral de recordar. Bogotá: Ediciones Uniandes, 2005.

Bolívar Jaime, Aura Patricia. "El derecho a la reparación integral y programas de reparación en perspectiva comparada" en Reparaciones en Colombia: análisis y propuestas, compilado por Rodrigo Uprimny Yepes, 71-143. Bogotá: Universidad Nacional de Colombia, 2009.

Castellanos Morales, Ethel Nathaly. Justicia transicional en Colombia. Formulación de propuestas desde un análisis comparado. Bogotá: Universidad Nacional de Colombia, 2008. 
Congreso de la República. Ley 1424 del 29 de diciembre de 2010, "Por la cual se dictan disposiciones de justicia transicional que garanticen verdad, justicia y reparación a las víctimas de desmovilizados de grupos organizados al margen de la ley, se conceden beneficios jurídicos y se dictan otras disposiciones". Bogotá: Diario Oficial No. 47.937, 29 de diciembre de 2010.

Congreso de la República. Ley 1448 de 2011, "Por la cual se dictan medidas de atención, asistencia y reparación integral a las víctimas del conflicto armado interno y se dictan otras disposiciones". Bogotá: Diario Oficial No. 48.096, 10 de junio de 2011.

Congreso de la República. Ley 975 de 2005, "Por la cual se dictan disposiciones para la reincorporación de miembros de grupos armados organizados al margen de la ley, que contribuyan de manera efectiva a la consecución de la paz nacional y se dictan otras disposiciones para acuerdos humanitarios". Bogotá: Diario Oficial No. 45.980, 25 de julio de 2005.

Consejo Nacional de Planeación. Retos del Plan Nacional de Desarrollo 2006-2010: Estado

Comunitario: desarrollo para todos. Una mirada desde la Sociedad Civil. Bogotá: Milenio Editores, 2007.

Corte Constitucional de Colombia. Sentencia C-052 del 8 de febrero de 2012. M. P. Nilson Pinilla Pinilla.

Corte Constitucional de Colombia. Sentencia C-1199 de diciembre 4 de 2008. M. P. Nilson Pinilla Pinilla.

Corte Constitucional de Colombia. Sentencia SU-090 del 2 de febrero de 2000. M. P. Eduardo Cifuentes Muñoz.

Corte Constitucional de Colombia. Sentencia T-025 del 22 de enero de 2004, M. P. Manuel José Cepeda Espinosa.

Cuervo, Jorge Iván. "Estándares internacionales de verdad, justicia y reparación. La aplicación de la Ley 975 de 2005 o Ley de 'Justicia y paz" en Justicia transicional: modelos y experiencias internacionales, a propósito de la ley de justicia y paz, editado por Jorge Iván Cuervo Restrepo, Eduardo Bechara Gómez y Verónica Hinestroza Arenas, 15-58. Bogotá: Universidad Externado de Colombia, 2007.

Díaz Gómez, Catalina, Nelson Camilo Sánchez y Rodrigo Uprimny Yepes. Reparar en Colombia. Los dilemas en contextos de conflicto, pobreza y exclusión. Bogotá: Centro Internacional para la Justicia Transicional, Unión Europea, DeJusticia, 2010.

Díaz, Ómar. "Los derechos de las víctimas de las violaciones a los derechos humanos" en La dimensión internacional de los derechos a la verdad, a la justicia y a la reparación para las victima de violaciones a los derechos humanos, editado o compilado por Eduardo Castellanos y Ómar Huertas, 42-68. Bogotá: Grupo Editorial Ibáñez, 2008.

Ferrer Llorét, Jaume. Responsabilidad internacional del Estado y derechos humanos: estudio de la práctica relacional e institucional. Madrid: Tecnos, Universidad de Alicante, 1998. 
Galeano, Eduardo. Las venas abiertas de América Latina. Bogotá: Tercer Mundo Editores, 1996.

Galeano, Eduardo. "Un amigo me pregunta cómo es Montevideo", en Nosotros decimos no. Crónicas 1963-1988, compilado por Eduardo Galeano, 259-264. Madrid: Tercer Mundo Editores, 1989.

Garay, Luis Jorge (dir.). Instituir una política integral de Verdad, Justicia y Reparación. Bogotá: Comisión de seguimiento a la política pública sobre desplazamiento forzado, Consultoría para los Derechos Humanos y el Desplazamiento [Codhes], 2011.

Gómez Isa, Felipe. "El derecho de las víctimas a la reparación por violaciones graves y sistemáticas de los derechos humanos". El otro Derecho, núm. 37 (2007): 11-64.

Gómez Méndez, María Paula. Una mirada hacia adelante: elementos para la reparación colectiva en Colombia. Bogotá: Fundación Social Konrad Adenauer Stiftung, 2006.

Gutiérrez Argüello, Soraya, Lucía Pacheco García, Elena Rey Maquieira Palmer, Corporación Colectivo de Abogados José Alvear Restrepo e Instituto Latinoamericano de Servicios Legales Alternativos (ILSA). La reparación integral, un derecho de las víctimas. Bogotá: Grupo de Trabajo Pro Reparación Integral, 2006.

Martínez Marulanda, Carlos Eduardo. "Aquí y en Cafarnaúm el que pega por atrás paga. Prolegómenos a un concepto de reparación para las víctimas con pretensiones de universalidad" en Reparaciones en Colombia: análisis y propuestas, compilado por Rodrigo Uprimny Yepes, 23-49. Bogotá: Universidad Nacional de Colombia, 2009.

Mejía Gómez, Camilo. La reparación integral con énfasis en las medidas de reparación no pecuniarias en el Sistema Interamericano de Derechos Humanos. Bogotá: Universidad Externado de Colombia, 2005.

Ministerio del Interior y de Justicia. Ley de víctimas y restitución de tierras. Bogotá: Imprenta Nacional de Colombia, 2011.

Najar Moreno, Esperanza. Derecho a la verdad y justicia transicional en el marco de aplicación de la Ley de Justicia y Paz. Bogotá: Grupo Editorial Ibáñez, 2009.

Organización de Estados Americanos [OEA]. Convención americana sobre derechos humanos. San José de Costa Rica, 1969.

Organización de las Naciones Unidas, Comisión de Derechos Humanos. Conjunto de principios para la protección y promoción de los derechos humanos mediante la lucha contra la impunidad. Washington, 8 de febrero de 2005.

Organización de las Naciones Unidas, Comisión de Derechos Humanos. Informe final acerca de la cuestión de impunidad de los autores de violaciones de los derechos humanos, derechos civiles y políticos, Washington, 2 de octubre de 1997.

Organización de las Naciones Unidas, Comisión de Derechos Humanos. Principios y directrices básicos sobre el derecho de las víctimas de violaciones de las normas internacionales de derechos humanos y del Derecho Internacional Humanitario a interponer recursos y 
obtener reparaciones. Resolución 60/147 aprobada por la Asamblea General de las Naciones Unidas. Washington, 16 de diciembre de 2005.

Organización de las Naciones Unidas, Comisión de Derechos Humanos. Principios y directrices básicas sobre el derecho de las víctimas de violaciones manifiestas de las normas internacionales de derechos humanos y de violaciones graves del Derecho Internacional Humanitario a interponer recursos y obtener reparaciones aprobados mediante Resolución No. 2005/35 del 18 de abril de 2005. Washington, 16 de diciembre de 2005.

Organización de Naciones Unidas. Declaración de las sobre los principios fundamentales de justicia para las víctimas de delitos y del abuso de poder, adoptada por la Asamblea General el 29 de noviembre de 1985 y anexa a la Resolución 40/34. Washington, 29 de noviembre de 1985.

Presidencia de la República de Colombia. Decreto 128 de enero 22 de 2003, "Por el cual se reglamenta la Ley 418 de 1997, prorrogada y modificada por la Ley 548 de 1999 y la Ley 782 de 2002 en materia de reincorporación a la sociedad civil”, modificado parcialmente por el Decreto Nacional 1059 de 2008. Bogotá: Diario Oficial No. 45.073, 24 de enero de 2003.

Presidencia de la República de Colombia. Decreto 1290 de abril 22 de 2008, "Por el cual se crea el Programa de Reparación Individual por Vía Administrativa para las Víctimas de los Grupos Armados Organizados al Margen de la Ley". Bogotá: Diario Oficial No. 46.968, 22 de abril de 2008.

Presidencia de la República de Colombia. Decreto 1725 de agosto 16 de 2012, "Por el cual se adopta el Plan Nacional de Atención y Reparación Integral a las Víctimas de que trata la Ley 1448 de 2011". Bogotá: Diario Oficial No. 48.525, 17 de agosto de 2012.

Presidencia de la República de Colombia. Decreto 2244 de junio 28 de 2011, "Por el cual se adicionan unas funciones al Centro de Memoria Histórica y se dictan otras disposiciones". Bogotá: Diario Oficial No. 48114, 28 de junio de 2011.

Presidencia de la República de Colombia. Decreto 2601 de julio 19 de 2011, "Por el cual se reglamenta la Ley 1424 de 2010”. Bogotá: Diario Oficial No. 48.137, 21 de julio de 2011.

Presidencia de la República de Colombia. Decreto 4633 de diciembre 9 de 2011, "Por medio del cual se dictan medidas de Asistencia, Atención, Reparación Integral y de Restitución de Derechos Territoriales a las Víctimas pertenecientes a los pueblos y Comunidades Indígenas". Bogotá: Diario Oficial No. 48.278, 9 de diciembre de 2011.

Presidencia de la República de Colombia. Decreto 4634 de diciembre 9 de 2011, "Por el cual se dictan medidas de asistencia, atención, reparación integral y restitución de tierras a las víctimas pertenecientes al pueblo rom o gitano". Bogotá: Diario Oficial No. 48.278, 9 de diciembre de 2011.

Presidencia de la República de Colombia. Decreto 4635 de diciembre 9 de 2011, "Por el cual se dictan medidas de asistencia, atención, reparación integral y de restitución de tie- 
rras a las víctimas pertenecientes a comunidades negras, afrocolombianas, raizales y palenqueras". Bogotá: Diario Oficial No. 48.278, 9 de diciembre de 2011.

Presidencia de la República de Colombia. Decreto 4800 de diciembre 20 de 2011, "Por el cual se reglamenta la Ley 1448 de 2011 y se dictan otras disposiciones". Bogotá: Diario Oficial No. 48.280, 20 de diciembre de 2011.

Presidencia de la República de Colombia. Decreto 4829 de diciembre 20 de 2011, "Por el cual se reglamenta el Capítulo IV de la Ley 1448 de 2011 en relación con la restitución de tierras". Bogotá: Diario Oficial No. 48.280, 20 de diciembre de 2011.

República de Colombia. Constitución Política de Colombia. Bogotá: Leyer, 2011.

Uprimny Yepes, Rodrigo, María Paula Saffon Sanín, Catalina Botero Marino y Esteban Restrepo Saldarriaga. ¿Justicia transicional sin transición? Verdad, justicia y reparación para Colombia. Bogotá: DeJusticia, 2006.

Uprimny Yepes, Rodrigo (comp.). Reparaciones en Colombia: análisis y propuestas. Bogotá: Universidad Nacional de Colombia, 2009.

Uprimny Yepes, Rodrigo. Reparaciones transformadoras de violaciones masivas a los derechos humanos: entre justicia correctiva y justicia distributiva. Bogotá: DeJusticia, 2009.

Van Zyl, Paul. "Promoviendo la Justicia Transicional en sociedades post-conflicto" en Verdad, memoria y reconstrucción. Estudios de caso y análisis comparado, editado por Mauricio Romero. Bogotá: Centro Internacional para la Justicia Transicional, 2008. 